YADONG WANG, Ph.D. ${ }^{1}$

E-mail: xwzj0003@gmail.com

QUAN SHI, Ph.D. ${ }^{1}$

(Corresponding author)

E-mail: airesearch01@gmail.com

ZHIFENG YOU, Ph.D. ${ }^{1}$

E-mail: junshiyc@163.com

QIWEI HU, Ph.D. ${ }^{1}$

E-mail: wana96100@gmail.com

${ }^{1}$ Department of Equipment Command and Management

Army Engineering University of PLA

No.96 Hepingxiroad, Xinhua District, Shijiazhuang,

050003, China
Transport Logistics Original Scientific Paper Submitted: 24 Dec. 2019 Accepted: 12 May 2020

\title{
INTEGRATION METHODOLOGY OF SPARE PARTS SUPPLY NETWORK OPTIMIZATION AND DECISION-MAKING
}

\begin{abstract}
In order to optimize the spare parts supply network, a multi-objective optimization model is established with the objectives of the shortest supply time, the lowest risk, and the minimum supply cost. A decomposition-based multi-objective evolutionary algorithm with differential evolution strategy is introduced to solve the multi-objective model. A series of non-dominated solutions, that is, representing the optimal spare parts supply schemes are obtained. In order to comprehensively measure the performance of these solutions, suitable quantitative metrics are selected, and the secondary goal-based cross-efficiency Data Envelopment Analysis (DEA) model has been used to evaluate the efficiency of the obtained optimal schemes. The improved DEA model overcomes the problems that the efficient units cannot be sorted and the optimal weight is not unique in traditional DEA model. Finally, the self-evaluation efficiency and cross-evaluation efficiency of each scheme are obtained, and the optimal supply scheme is found based on their cross-evaluation efficiency.
\end{abstract}

\section{KEY WORDS}

spare parts supply; multi-objective optimization; data envelopment analysis; cross-efficiency;

\section{INTRODUCTION}

The optimization problem of spare parts supply needs to consider many factors, such as time, risk, cost, and so on [1]. The optimization objectives are multiple, so the corresponding model is difficult to be solved. Therefore, the optimization and decision-making of spare parts supply are critical and a difficult issue for industry manufacture and maintenance.

At present, most of the research work is focused on spare parts supply network optimization. Wei et al. studied the wartime spare parts scheduling model under the condition of insufficient resources. They took the earliest supply start time and the least transfer line as objectives, and the multi-objective model was transformed into single-objective optimization by the weighting method [2]. Liu et al. established a multi-stage spare parts supply support planning model under the typical three-stage supply network, and established an unconstrained single-objective optimization model aiming at minimizing the spare parts shortage [3]. Zhang et al. established a multi-objective material supply optimization model based on the credibility theory, and the bat algorithm was used to solve the multi-objective optimization problem [4]. In order to minimize the supply costs, Qin et al. established an optimization model of emergency resource allocation considering the constraints of the number of emergency resources, reserve capacity, and location. The model was solved by using a genetic algorithm with matrix real number coding [5]. Fazli et al. established a three-objective optimization model of emergency supply network in order to minimize the total supply cost and transportation time while maximizing the supply reliability [6]. Zhang et al. established a multi-objective three-stage stochastic programming model with the objectives of minimum lead time 
and costs, and adopted the substitute fuzzy auxiliary variables to deal with the multi-objective model [7]. Mohammadi et al. took the maximum demand, minimum cost, and the maximum satisfaction rate as the objectives of their multi-objective stochastic programming model, and used the multi-objective particle swarm optimization algorithm to solve their model [8]. Su et al. constructed a two-objective integer linear programming model with the goal of minimizing the response time and emergency resource cost, and used the differential evolution algorithm to search the optimal solutions of the model [9].

It can be seen that the related research work can be divided into single-objective optimization model and multi-objective optimization model. The multi-objective optimization model is more reasonable for spare parts supply; however, it is difficult to be solved and can hardly obtain the unique optimal solution. Therefore, this paper firstly constructs a multi-objective spare parts supply network optimization model with the objective of minimum supply time, risk, and costs. Secondly, an improved multi-objective evolutionary algorithm is used to solve the model, and the non-dominated feasible solutions are obtained. Finally, the evaluation metrics is calculated and these optimal solutions are evaluated and sorted based on their efficiency, and the solution with the largest cross-efficiency is the optimal supply scheme.

\section{MULTI-OBJECTIVE SPARE PARTS SUPPLY OPTIMIZATION MODEL}

\subsection{Problem description}

Spare parts supply network consists of three-echelon nodes, that is, manufacturers, distribution centres, and customers. The spare parts are supplied from the manufacturers to the distribution centres, and then distributed to the customers. The proposed model should meet the spare parts demands with the shortest supply time, the lowest risk, and the least costs.

The spare parts supply model in this paper is based on the following assumptions: (1) Take a certain kind of critical spare parts as the research object. (2) The transportation cost and transportation time are known and fixed. (3) The opening cost (the fixed cost of setting up and operating facilities), inventory cost, and maximum capacity of distribution centres are known and fixed. (4) The spare parts are distributed to the customers in a unified time after all the spare parts have arrived at the distribution centres. (5) The disruption risk of the supply network occurs only between the distribution centres and customers.

\subsection{Parameters}

I $\quad$ - index of manufacturers, $i=1,2, \ldots, I$;

$J \quad-$ index of distribution centres, $j=1,2, \ldots, J$;

$K \quad$ - index of customers, $k=1,2, \ldots, K$;

$U_{j} \quad$ - maximum capacity of distribution centre $j$

$C_{j}^{\text {open }}$ - opening cost of distribution centre $j$;

$C_{j}^{\text {inven }}$ - inventory cost of distribution centre $j$;

$d_{k} \quad$ - spare parts demand of customer $k$;

$C_{k}^{\text {short }}$ - shortage cost of customer $k$;

$T_{k}^{\text {lead }}$ - maximum lead time of customer $k$;

$T_{i j}^{t r a n s}$ - unit transport time between manufacturer $i$ and distribution centre $j$;

$T_{j k}^{\text {trans }}$ - unit transport time between distribution centre $j$ and customer $k$;

$C_{i j}^{\text {trans }}$ - unit transport cost between manufacturer $i$ and distribution centre $j$;

$C_{j k}^{\text {trans }}-$ unit transport cost between distribution centre $j$ and customer $k$;

$R_{j k} \quad$ - disruption risk between distribution centre $j$ and customer $k$;

decision variables

$x_{i j} \quad$ number of shipments from manufacturer $i$ to distribution centre $j$;

$x_{j k} \quad$ number of shipments from distribution centre $j$ to customer $k$;

$y_{j} \quad$ - binary variable,

$y_{j}=\left\{\begin{array}{l}1, \text { if distribution centre } j \text { is open } \\ 0, \text { otherwise }\end{array}\right.$

\subsection{Modelling}

The first objective of the supply model is the minimum supply time:

$$
\min \sum_{i \in I} \sum_{j \in J} T_{i j}^{\text {trans }} \cdot x_{i j}+\sum_{j \in J} \sum_{k \in K} T_{j k}^{\text {trans }} \cdot x_{j k}
$$

The second objective is the lowest risk, which is formulated as follows:

$\min \sum_{j \in J} \sum_{k \in K} R_{j k} \cdot \operatorname{sgn}\left(x_{j k}\right)$

where, $\operatorname{sgn}(x)=\left\{\begin{array}{l}0, \text { if } x=0 \\ 1, \text { if } x>0 \\ -1, \text { if } x<0\end{array}\right.$ is step function.

The third objective is the minimum supply costs, which is shown as follows: 
$\min C=C^{\text {open }}+C^{\text {trans }}+C^{\text {invent }}+C^{\text {short }}$

where, $C^{o p e n}$ is the opening cost of distribution centres, $C^{\text {trans }}$ is the transportation cost, $C^{\text {invent }}$ is the inventory cost of distribution centres, and $C^{\text {short }}$ is the shortage cost. The costs are calculated as follows:

$$
\begin{aligned}
& C^{\text {open }}=\sum_{j \in J} C_{j}^{\text {open }} \cdot y_{j} \\
& C^{\text {trans }}=\sum_{i \in I} \sum_{j \in J} C_{i j}^{\text {trans }} \cdot x_{i j}+\sum_{j \in J} \sum_{k \in K} C_{j k}^{\text {trans }} \cdot x_{j k} \\
& C^{\text {invent }}=\sum_{j \in J} C_{j}^{\text {invent }} \cdot\left(\sum_{i \in I} x_{i j}-\sum_{k \in K} x_{j k}\right) \\
& C^{\text {short }}=\sum_{k \in K} C_{k}^{\text {short }} \cdot\left|d_{k}-\sum_{j \in J} x_{j k}\right|
\end{aligned}
$$

The model satisfies the following constraints:

$$
\begin{aligned}
& \sum_{i \in I} x_{i j} \leq y_{j} \cdot U_{j} \quad j=1,2, \ldots, J \\
& \sum_{k \in K} x_{j k} \leq y_{j} \cdot U_{j} \quad j=1,2, \ldots, J \\
& d_{k} \leq \sum_{j \in J} x_{j k} \quad k=1,2, \ldots, K \\
& \sum_{k \in K} x_{j k} \leq \sum_{i \in I} x_{i j} \quad j=1,2, \ldots, J \\
& \max \left\{T_{i j}^{\text {trans }} \cdot \operatorname{sgn}\left(x_{i j}\right) \mid i \in I, j \in J\right\}+ \\
& +\max \left\{T_{j k}^{\text {trans }} \cdot \operatorname{sgn}\left(x_{j k}\right), j \in J\right\} \leq T_{k}^{\text {lead }} \\
& k=1,2, \ldots, K \\
& x_{i j} \in N^{+}, \quad x_{j k} \in N^{+}, \quad y_{j}=\{0,1\}
\end{aligned}
$$

where, Constraints 8 and 9 indicate that the closed distribution centres do not participate in the spare parts supply. They also specify that the number of supplied spare parts should not exceed the maximum capacity of the distribution centres. Constraint 10 states that the spare parts demands of the customers must be met. Constraint 11 states that the output should not exceed the input of spare parts in each distribution centre. Constraint 12 specifies that the lead time of spare parts supply should not exceed the maximum allowable deadline. Constraint 13 specifies the type and range of decision variables.

\section{IMPROVED MULTI-OBJECTIVE OPTIMIZATION ALGORITHM}

The spare parts supply model developed in this paper is a multi-objective optimization model, and can be hardly solved by using the exact algorithm. At present, the meta-heuristic algorithm such as evolutionary computing and swarm intelligence are widely used. The meta-heuristic algorithm does not need prior knowledge of the optimization problem, and can deal with large-scale optimization problems in parallel computing. Therefore, this paper adopts an improved multi-objective evolutionary algorithm based on the decomposition algorithm (MOEA/D) to solve the model.

\subsection{Tchebycheff decomposition strategy}

The basic idea of MOEA/D algorithm is to decompose the multi-objective optimization problem into multiple single-objective optimization sub-problems and optimize them at the same time. The most common used decomposition methods are the weighted sum approach [10], Tchebycheff approach [11], penalty-based boundary intersection approach [12], and so on. In this paper, the Tchebycheff approach is adopted as the decomposition strategy, and the expression of the $i$-th sub-question is as follows:

$\min g^{t e}\left(x^{i} \mid \lambda^{i}, z^{*}\right)=\max _{1 \leq j \leq m}\left\{\lambda_{j}^{i} \mid f_{j}(x)-z_{j}^{*}\right\}$

where, $i=1,2, \ldots, N$ is the index of sub-question, $N$ is the size of the population (also the number of sub-problems); $j=1,2, \ldots, M$ is the index of objectives, $\lambda^{i}=\left(\lambda_{1}^{i}, \lambda_{2}^{i}, \ldots, \lambda_{M}^{i}\right)$ represents the weight vector of the $i$-th sub-problem, $\sum_{j=1}^{M} \lambda_{j}^{i}=1, M$ is the amount of objectives; $z^{*}=\left(z_{1}^{*} z_{2}^{*}, \ldots, z_{M}^{*}\right)$ is the set of reference point vector, $f(x)$ is the objective function. For the minimization problem, there is $z_{j}^{*}=\min \left\{f_{j}(x) \mid x \in \Omega\right\}$. The principle of Tchebycheff decomposition strategy to ensure the population convergence is explained in literature [13]. They also proved that if the individual vector $x^{i}$ is satisfied, Equation 14 with the weight vector $\lambda^{i}=\left(\lambda_{1}^{i}, \lambda_{2}^{i}, \ldots, \lambda_{M}^{i}\right)$, then, $x^{i}$ is also the Pareto optimal solution of multi-objective optimization problem, which is not discussed in this paper.

\subsection{Evolution strategy}

Because the sub-problems in MOEA/D are defined by specific weight vectors, when the weight vector of the two sub-problems is similar, the Pareto optimal solution of the corresponding sub-problem is also similar. Therefore, the MOEA/D algorithm introduces the concept of neighbourhood, that is, neighbourhood $B(i)=\left(i^{1}, i^{2}, \ldots, i^{T}\right)$ of a sub-problem is composed of $T$ neighbour problems closest to it. The original MOEA/D algorithm selects two individuals (sub-problems) from the neighbourhood of the sub-problem as the parent individuals, then generates the offspring individual by crossover and mutation. In this paper, the differential evolution strategy is 
used to generate the offspring individuals. At the same time, in order to ensure the diversity of the population, a perturbation operator is set up, that is, the parent individuals are selected from the population with a certain probability rather than from its neighbourhood completely.

The Differential Evolutionary algorithm (DE) provides a multivariate evolutionary mechanism for evolutionary algorithms. In this paper, the "DE/ rand/1" mutation strategy is adopted:

$u^{i}=x_{r 1}+F \cdot\left(x_{r 2}-x_{r 3}\right)$

where, $u^{i}$ is mutation individual, $x_{r 1}, x_{r 2}, x_{r 3}$ are parent individuals, $r 1 \neq r 2 \neq r 3 . F \in[0,1]$ is mutation factor. In this paper, $x_{r 1}$ and $x_{r 2}$ are selected from the neighbourhood of the sub-problem, $x_{r 3}$ is selected from the population with certain probability to ensure the diversity of evolution:

$x_{r 3} \in\left\{\begin{array}{l}B(i), \text { rand } \leq \delta \\ P(x), \text { else }\end{array}\right.$

where, $B(i)$ is the neighbourhood of $x^{i}, P(x)$ is the population, rand is a random number between $(0,1)$, $\delta \in(0,1)$ is the selection threshold.

The crossover individual vector $v^{i}$ is generated from the original individual $x_{r 1}$ and the mutation individual $u^{i}$ by the crossover operation:

$v^{i}=\left\{\begin{array}{l}u^{i}, \text { if }\left(\text { rand }_{i j} \leq \mathrm{CR}\right) \\ x_{r}, \text { otherwise }\end{array}\right.$

where, randi is a uniform distributed number between $[0,1]$, and $\mathrm{CR} \in[0,1]$ is the crossover rate. It can be seen that the greater the value of $C R$, the greater the probability of cross operation.

The values of fitness functions of the parental individual $x_{r 1}$ and the crossover individual $v^{i}$ were calculated respectively. According to the Pareto dominance relationship between them, the non-dominant individual is selected as the offspring individuals $y^{i}$.

\subsection{Fitness function}

Since the multi-objective optimization model developed in this paper belongs to the constrained optimization problem, a dynamic penalty function method is used to deal with constraints [14]:

$$
f(\bar{x})=O(\bar{x})+\left(M_{0}-\frac{i \text { ter }}{\max \text { iter }} \cdot M_{K}\right) \cdot P(\bar{x})
$$

where, $f(\bar{x})$ is the fitness function, $O(\bar{x})$ is the objective function; $M_{0}$ is initial penalty factor, iter are current iterations of the algorithm; maxiter is the maximum number of iterations; $M_{K}$ is the penalty coefficient; $P(\bar{x})$ is constraint violation, which is formulated as follows:

$P(\bar{x})=\sum_{j=1}^{m} c_{j}(\bar{x})$

where, for the inequality constraints, there is $c_{j}(\vec{x})=\max \left(0, l_{j}(\bar{x})\right)$, where $l_{j}(\vec{x}) \leq 0$ is the $j$-th inequality constraint of the model; for the equality constraints, there is $c_{j}(\vec{x})=\max \left(0,\left|h_{j}(\vec{x})-\varepsilon\right|\right)$, where $h_{j}(\bar{x})=0$ is the $j$-th equality constraint of the model, $\varepsilon$ is a very small real number.

\subsection{Framework of improved MOEA/D algorithm}

The basic steps of the improved MOEA/D algorithm are shown in the following algorithm:

Inputs:

Multi-objective Optimization problem (Equations 1-13)

Termination rules

$N$ - The number of sub-problems (individuals), the number of weight vectors (population size).

The weight vector of uniform distribution

$T$ - Neighbourhood size of sub-problems

Mutation factor $F$, Equation 15

Selection threshold $\delta$, Equation 16

Outputs:

Archive

Step 1: Initialize

1.1 Calculate the Euclidean distance between weight vectors $\lambda_{1}$, select the nearest $T$ sub-problem to form neighbourhood $B(i)$.

1.2 Initialize the population randomly and calculate the fitness function of the population.

1.3 According to the Pareto dominance relationship of the individual, the non-dominant individuals in the population are put into the archive.

1.4 Initializing reference points $z$.

Step 2: Iteration

while termination condition has not been met

for $i=1: N$

2.1 Using evolutionary mechanism of section 3.2 to produce offspring individuals $y$.

2.2 Correction. If the variables of the new individual exceed the range of decision variables, then the variables are modified.

2.3 Update the reference point. For each $j=1,2, \ldots, M$, if $f_{j}\left(y^{\prime}\right) \leq z_{j}$, then $z_{j}=f_{j}\left(y^{\prime}\right)$.

2.4 Update the neighbourhood. Update the neighbourhood according to the feasibility rules, if $y$ is better than individual in neighbourhood $i^{t} \in B(i)$, then replace $i^{t}$ by $y$.

2.5 Update the archiving, mix the new population with the archive, and take the non-dominant solution of the mixed population as the new archive.

end for

end while

The final archive is the set of optimal solutions. 


\section{SECONDARY GOAL-BASED CROSS-EFFICIENCY DEA EVALUATION}

The result of multi-objective optimization is not a unique optimal solution, but a series of Pareto optimal solutions. These Pareto optimal solutions cannot be further selected based on their dominating relation. Therefore, this paper further evaluates these non-dominant solutions from the aspects of reliability, timeliness, economy, and so on.

By using the MOEA/D algorithm, the exact values of all the metrics of these Pareto optimal solutions can be calculated, then, DEA is adopted to evaluate and sort these solutions. The traditional DEA was proposed by Cooper et al. His CCR model with constant returns to scale is as follows [15]:

$$
\begin{aligned}
& \max E_{d d}=\frac{\sum_{r=1}^{s} \mu_{r d} \cdot y_{r d}}{\sum_{i=1}^{m} v_{i d} \cdot x_{i d}} \\
& \text { s.t. } \quad E_{j}=\frac{\sum_{r=1}^{s} \mu_{r j} \cdot y_{r j}}{\sum_{i=1}^{m} v_{i j} \cdot x_{i j}} \leq 1 \quad j=1,2, \ldots, n \\
& \mu_{r d} \geq \varepsilon \quad v_{i j} \geq \varepsilon \quad r=1,2, \ldots, s \quad i=1,2, \ldots, m
\end{aligned}
$$

where, $y_{r j}$ is the $r$-th output of the $j$-th decision-making units (DMUs), $\mu_{r j}$ is the weight of $y_{r j} ; x_{i j}$ is the $i$-th input of $D M U_{j}, v_{i j}$ is the weight of $x_{i j}$. The objective $E_{d d}$ is the self-evaluation efficiency of $D M U_{d}$. Constraint 21 specifies that the efficiency of each DMU should be between 0 and 1. Constraint 22 states that all the weights should be greater than $0, \varepsilon$ is a non-Archimedes number that is smaller than any positive number.

In the CCR model, if the efficiency of DMU is equal to 1 , it indicates that this DMU is efficient, and if the efficiency is less than 1, it is inefficient. Therefore, the traditional CCR model can distinguish between the efficient DMUs and the inefficient DMUs; however, it cannot sort further the efficient DMUs. In order to further distinguish the efficient DMUs, the traditional DEA has been improved by many scholars, such as cross-efficiency evaluation [16], super-efficiency evaluation [17], benchmark evaluation, and so on. In this paper, the cross-efficiency DEA method is used to sort both the efficient and the inefficient DMUs.
It is assumed that $E_{d d}^{*}$ is the self-evaluation efficiency of $D M U_{d}$ obtained by the CCR model, $\mu_{r d}^{*}, v_{i d}^{*}$ are the corresponding weights. Then, the cross-evaluation efficiency of $D M U_{j}$ relative to $D M U_{d}$ is calculated as follows:

$E_{d j}=\frac{\sum_{r=1}^{s} \mu_{r d}^{*} \cdot y_{r j}}{\sum_{i=1}^{m} v_{i d}^{*} \cdot y_{i j}}$

The self-evaluation efficiency of each DMU is obtained by using the CCR model, and the cross-evaluation efficiency of each DMU can be obtained according to Equation 23. Then the cross-evaluation efficiency matrix can be obtained:

$E=\left[\begin{array}{cccc}E_{11} & E_{12} & \ldots & E_{1 n} \\ E_{21} & E_{22} & \ldots & E_{2 n} \\ \vdots & \vdots & \vdots & \vdots \\ E_{n 1} & E_{n 2} & \ldots & E_{n n}\end{array}\right]$

The cross-evaluation efficiency of $D M U_{j}$ is as follows:

$$
C E_{j}=\frac{1}{n} \sum_{d=1}^{n} E_{d j}
$$

However, the cross-efficiency DEA still has its shortcomings, that is, the optimal weight combination obtained by CCR may not be unique, so the cross-evaluation efficiency calculated by Formulation 23 is not unique either. To overcome such problems, Doyle et al. proposed a DEA method with secondary goals [18]. The most common used secondary goals include aggressive strategy and benevolent strategy [19]. In this paper, by using a DEA model proposed by Wang et al., the unique optimal weight combination can be obtained and the cross-evaluation efficiency of each DMUs can be calculated with Equations 23 and 24. The improved model is shown as follows [20]:

$$
\begin{aligned}
& \min I_{d}=\sum_{j=1}^{n} z_{j}^{d} \\
& \text { s.t. } \sum_{r=1}^{s} \mu_{r d} \cdot y_{r d}-\sum_{i=1}^{m} v_{i d} \cdot x_{i d} \leq 0, \quad j=1,2, \ldots, n \\
& \sum_{i=1}^{m} v_{i d} \cdot x_{i d}=1 \\
& \sum_{r=1}^{s} \mu_{r d} \cdot y_{r d}=E_{d d} \\
& \sum_{r=1}^{s} \mu_{r d} \cdot y_{r j} \\
& \sum_{i=1}^{m} v_{i d} \cdot y_{i j} \\
& 0 \leq h_{j}^{d}+M \cdot h_{j}^{d}=\frac{\sum_{r=1}^{s} \mu_{r d} \cdot y_{r d}}{\sum_{i=1}^{m} v_{i d} \cdot x_{i d}}, j=1,2, \ldots, n, \quad j=1,2, \ldots, n \\
& z_{j}^{d}=\{0,1\}, \quad j=1,2, \ldots, n
\end{aligned}
$$


$h_{j}^{d} \in R$

$\mu_{r j} \geq \varepsilon \quad r=1,2, \ldots, S$

$v_{i j} \geq \varepsilon \quad i=1,2, \ldots, m$

where, $M$ is a very large positive number, $\varepsilon$ is a non-Archimedes constant. Constraints 27-29 specify the value of self-evaluation efficiency. Since Constraint 32 specifies that the value of $z_{j}^{d}$ can only be between 0 and 1 , when $z_{j}^{d}=0$, Constraint 31 ensures $h_{j}^{d} \geq 0$. At this time, Constraint 30 ensures that the efficiency of $D M U_{d}$ is greater than that of $D M U_{j}$. Similarly, when $z_{j}^{d=1}$, Constraint 31 ensures $h_{j}^{d} \leq \varepsilon$. Constraint 30 ensures that the efficiency of $D M U_{d}$ is smaller than that of $D M U_{j}$. The objective function aims to obtain a set of weights to minimize $I_{d}=\sum_{j=1}^{n} z_{j}^{d}$, that is, to ensure the value of $z_{j}^{d}$ to be zero. It can be seen that the improved secondary goal cross-efficiency DEA model can sort the efficient DMUs, and guarantee the efficiency of $D M U_{d}$ is larger than that of other DMUs.

\section{EXPERIMENT AND ANALYSIS}

\subsection{Experiment description}

There are two manufacturers, four alternative distribution centres and six customers in a supply network. Spare parts are shipped from manufacturers to distribution centres, and transferred to customers from distribution centres according to customers' demands. The related data of manufacturers, distribution centres and customers are shown in Tables 1-5.

Table 1 - Unit spare parts transportation time
According to the nature of DEA model, the evaluation metrics is divided into input metrics and output metrics.

The input metrics includes:

- Supply cost: the calculation formula is shown as Objective function 3;

- Supply time: the calculation formula is shown as Objective function 1.

The output metrics includes:

- Reliability: measured by the risk of spare parts supply, the value of reliability is the reciprocal of the total risk. The calculation formula of risk is shown as Objective function 2

- Timeliness: measured by lead time, the value of timeliness is the reciprocal of the lead time. The calculation formula of lead time is shown as Constraint 12;

- Fill rate: calculated as the ratio of spare parts supply and demand of each customer.

Constraint violation: Because the model also involves the constraints of capacity and flow balance, the reciprocal of the overall constraint violation of the model is used as one of the output metrics, and the calculation of overall constraint violation is shown as Equation 18.

The numerical experiments are solved by the improved MOEA/D algorithm. The simulation studies were carried out in a MATLAB 2014b platform on an ASUS laptop with 5-6300HQ 2.3GBz CPU, 4GB RAM in Windows 7.0(64-bit) environment. The related parameters are set as follows: population size is 200 , archiving size is 100 , maximum number of iterations maxiter $=500$, neighbourhood size $T=20$, mutation factor $F=0.9$, selection threshold $\delta=0.8$, crossover rate $\mathrm{CR}=0.8$, initial penalty factor $M_{0}=10,000,000$, penalty coefficient $M_{k}=10,000$.

\begin{tabular}{|c|c|c|c|c||}
\hline & Distribution centre 1 & Distribution centre 2 & Distribution centre 3 & Distribution centre 4 \\
\hline \hline Manufacturer1 & 36 & 40 & 42 & 32 \\
\hline Manufacturer2 & 24 & 33 & 35 & 46 \\
\hline Customer1 & 6 & 5 & 5 & 4 \\
\hline Customer2 & 2 & 3 & 6 & 3.5 \\
\hline Customer3 & 2.5 & 5 & 5 & 5.5 \\
\hline Customer4 & 4 & 2 & 2.5 & 4 \\
\hline Customer5 & 6 & 6.5 & 6.5 & 3 \\
\hline Customer6 & 5 & 5 & & 6 \\
\hline
\end{tabular}


Wang Y, Shi Q, You Z, Hu Q. Integration Methodology of Spare Parts Supply Network Optimization and Decision-making

Table 2 - Unit spare parts transportation time costs

\begin{tabular}{||c|c|c|c|c||}
\hline & Distribution centre 1 & Distribution centre 2 & Distribution centre 3 & Distribution centre 4 \\
\hline \hline Manufacturer1 & 260 & 240 & 320 & 350 \\
\hline Manufacturer2 & 330 & 280 & 270 & 160 \\
\hline Customer1 & 80 & 82 & 76 & 60 \\
\hline Customer2 & 65 & 70 & 75 & 65 \\
\hline Customer3 & 58 & 50 & 65 & 66 \\
\hline Customer4 & 70 & 72 & 80 & 65 \\
\hline Customer5 & 66 & 56 & 60 & 57 \\
\hline Customer6 & 70 & 55 & 62 & 75 \\
\hline
\end{tabular}

Table 3 - Disruption risk between distribution centres and customers

\begin{tabular}{|c|c|c|c|c||}
\hline & Distribution centre 1 & Distribution centre 2 & Distribution centre 3 & Distribution centre 4 \\
\hline \hline Customer1 & 0.08 & 0.20 & 0.16 & 0.04 \\
\hline Customer2 & 0.16 & 0.12 & 0.15 & 0.05 \\
\hline Customer3 & 0.08 & 0.05 & 0.05 & 0.35 \\
\hline Customer4 & 0.17 & 0.09 & 0.10 & 0.12 \\
\hline Customer5 & 0.16 & 0.01 & 0.06 & 0.11 \\
\hline Customer6 & 0.27 & 0.05 & 0.25 & 0.06 \\
\hline
\end{tabular}

Table 4 - Inventory capacity, unit spare parts inventory cost, and opening cost of distribution centres

\begin{tabular}{||c|c|c|c|c||}
\hline & Distribution centre 1 & Distribution centre 2 & Distribution centre 3 & Distribution centre 4 \\
\hline \hline Inventory capacity & 35 & 25 & 20 & 30 \\
\hline Unit inventory cost & 20 & 30 & 15 & 25 \\
\hline Unit opening cost & 8,000 & 7,500 & 5,000 & 8,500 \\
\hline
\end{tabular}

Table 5 - Spare parts demands, shortage loss, and the maximum lead time of customers

\begin{tabular}{||c|c|c|c||}
\hline \hline & Demand & $\begin{array}{c}\text { Shortage } \\
\text { cost }\end{array}$ & $\begin{array}{c}\text { Maximum } \\
\text { lead time }\end{array}$ \\
\hline \hline Customer1 & 12 & 500 & 55 \\
\hline Customer2 & 20 & 550 & 50 \\
\hline Customer3 & 18 & 500 & 55 \\
\hline Customer4 & 5 & 600 & 53 \\
\hline Customer5 & 16 & 500 & 55 \\
\hline Customer6 & 15 & 500 & 55 \\
\hline
\end{tabular}

\subsection{Results and analysis}

By using the improved MOEA/D, we got 24 non-dominated solutions which are shown in Table 6. Each column represents an optimal solution and each row represents the variables on the solution vector. These solutions provided 24 available supply schemes for the decision maker. It is further necessary to pick up the optimal one from them.
Since these 24 schemes are non-dominated with each other, it is difficult to choose the optimal one only based on their fitness functions. Therefore, DEA method is used to evaluate and sort these 24 schemes further. The metrics of obtained non-dominated solutions are calculated and shown in Table 7. The supply cost, supply time and the risk corresponding to each solution can be visually observed in Table 7 . It can also be seen that the spare parts fill rates of all the customers are greater than 1 , that is, all solutions can meet the spare parts demand of all customers.

In order to verify the superiority of our method compared with the traditional self-evaluation DEA, the self-evaluation efficiency and secondary goal-based cross-evaluation efficiency of all DMUs are obtained respectively. The efficiencies are shown in Figure 1.

It can be seen that, by using DEA, decision maker are able to distinguish the efficient solutions from these non-dominated solutions. However, there are 
Wang Y, Shi Q, You Z, Hu Q. Integration Methodology of Spare Parts Supply Network Optimization and Decision-making

Table 6-Set of optimal supply schemes

\begin{tabular}{|c|c|c|c|c|c|c|c|c|c|c|c|c|c|c|c|c|c|c|c|c|c|c|c|c|}
\hline $\mathrm{X}$ & 1 & 2 & 3 & 4 & 5 & 6 & 7 & 8 & 9 & 10 & 11 & 12 & 13 & 14 & 15 & 16 & 17 & 18 & 19 & 20 & 21 & 22 & 23 & 24 \\
\hline X1 & 35 & 35 & 35 & 35 & 35 & 35 & 35 & 35 & 35 & 35 & 35 & 35 & 35 & 35 & 35 & 35 & 35 & 35 & 35 & 35 & 35 & 35 & 35 & 35 \\
\hline $\mathrm{X} 2$ & 0 & 0 & 0 & 0 & 0 & 0 & 0 & 0 & 0 & 0 & 1 & 1 & 1 & 1 & 1 & 1 & 1 & 1 & 1 & 1 & 2 & 2 & 3 & 4 \\
\hline X3 & 0 & 0 & 0 & 0 & 0 & 0 & 0 & 0 & 0 & 0 & 0 & 0 & 0 & 0 & 0 & 0 & 0 & 0 & 0 & 0 & 0 & 0 & 0 & 0 \\
\hline X4 & 0 & 0 & 0 & 0 & 0 & 0 & 0 & 0 & 0 & 0 & 0 & 0 & 0 & 0 & 0 & 0 & 0 & 0 & 0 & 0 & 0 & 0 & 0 & 0 \\
\hline X5 & 0 & 0 & 0 & 0 & 0 & 0 & 0 & 0 & 0 & 0 & 0 & 0 & 0 & 0 & 0 & 0 & 0 & 0 & 0 & 0 & 0 & 0 & 0 & 0 \\
\hline X6 & 19 & 20 & 22 & 22 & 22 & 22 & 22 & 23 & 23 & 25 & 19 & 19 & 20 & 21 & 21 & 21 & 22 & 23 & 23 & 24 & 18 & 20 & 18 & 16 \\
\hline $\mathrm{X} 7$ & 11 & 12 & 11 & 12 & 13 & 13 & 14 & 11 & 13 & 12 & 11 & 13 & 12 & 11 & 12 & 13 & 12 & 12 & 13 & 13 & 10 & 12 & 11 & 10 \\
\hline X8 & 24 & 24 & 26 & 26 & 25 & 26 & 27 & 25 & 25 & 24 & 26 & 24 & 25 & 26 & 25 & 25 & 24 & 26 & 26 & 25 & 27 & 24 & 25 & 25 \\
\hline X9 & 9 & 9 & 9 & 9 & 9 & 9 & 9 & 9 & 9 & 9 & 9 & 9 & 9 & 9 & 9 & 9 & 9 & 9 & 9 & 9 & 9 & 9 & 9 & 9 \\
\hline $\mathrm{X} 10$ & 0 & 0 & 0 & 0 & 0 & 0 & 0 & 0 & 0 & 0 & 0 & 0 & 0 & 0 & 0 & 0 & 0 & 0 & 0 & 0 & 0 & 0 & 0 & 0 \\
\hline $\mathrm{X} 11$ & 19 & 19 & 18 & 18 & 18 & 19 & 18 & 21 & 18 & 19 & 18 & 21 & 18 & 19 & 19 & 18 & 18 & 19 & 18 & 18 & 18 & 20 & 19 & 18 \\
\hline $\mathrm{X} 12$ & 0 & 0 & 0 & 0 & 0 & 0 & 0 & 0 & 0 & 0 & 0 & 0 & 0 & 0 & 0 & 0 & 0 & 0 & 0 & 0 & 0 & 0 & 0 & 0 \\
\hline $\mathrm{X} 13$ & 0 & 0 & 0 & 0 & 0 & 0 & 0 & 0 & 0 & 0 & 0 & 0 & 0 & 0 & 0 & 0 & 0 & 0 & 0 & 0 & 0 & 0 & 0 & 0 \\
\hline X14 & 6 & 5 & 3 & 2 & 2 & 0 & 0 & 1 & 1 & 0 & 6 & 3 & 3 & 2 & 2 & 1 & 3 & 0 & 0 & 0 & 5 & 2 & 4 & 6 \\
\hline $\mathrm{X} 15$ & 0 & 0 & 0 & 0 & 0 & 0 & 0 & 0 & 0 & 0 & 0 & 0 & 0 & 0 & 0 & 0 & 0 & 0 & 0 & 0 & 0 & 0 & 0 & 0 \\
\hline X16 & 10 & 9 & 9 & 9 & 8 & 7 & 6 & 9 & 8 & 9 & 10 & 7 & 8 & 9 & 8 & 7 & 9 & 9 & 8 & 10 & 10 & 8 & 9 & 10 \\
\hline $\mathrm{X} 17$ & 0 & 0 & 0 & 0 & 0 & 0 & 0 & 0 & 0 & 0 & 0 & 0 & 0 & 0 & 0 & 0 & 0 & 0 & 0 & 0 & 0 & 0 & 0 & 0 \\
\hline X18 & 0 & 0 & 0 & 0 & 0 & 0 & 0 & 0 & 0 & 0 & 0 & 0 & 0 & 0 & 0 & 0 & 0 & 0 & 0 & 0 & 0 & 0 & 0 & 0 \\
\hline X19 & 0 & 0 & 0 & 0 & 0 & 0 & 0 & 0 & 0 & 0 & 0 & 0 & 0 & 0 & 0 & 0 & 0 & 0 & 0 & 0 & 0 & 0 & 0 & 0 \\
\hline $\mathrm{X} 20$ & 9 & 11 & 12 & 13 & 13 & 15 & 15 & 14 & 14 & 16 & 9 & 12 & 12 & 13 & 13 & 14 & 12 & 15 & 15 & 15 & 10 & 14 & 11 & 9 \\
\hline $\mathrm{X} 21$ & 0 & 0 & 0 & 0 & 0 & 0 & 0 & 0 & 0 & 0 & 0 & 0 & 0 & 0 & 0 & 0 & 0 & 0 & 0 & 0 & 0 & 0 & 0 & 0 \\
\hline X22 & 10 & 11 & 11 & 11 & 12 & 13 & 14 & 11 & 12 & 11 & 10 & 13 & 12 & 11 & 12 & 13 & 11 & 11 & 12 & 10 & 10 & 12 & 11 & 10 \\
\hline $\mathrm{X} 23$ & 0 & 0 & 0 & 0 & 0 & 0 & 0 & 0 & 0 & 0 & 0 & 0 & 0 & 0 & 0 & 0 & 0 & 0 & 0 & 0 & 0 & 0 & 0 & 0 \\
\hline $\mathrm{X} 24$ & 0 & 0 & 0 & 0 & 0 & 0 & 0 & 0 & 0 & 0 & 0 & 0 & 0 & 0 & 0 & 0 & 0 & 0 & 0 & 0 & 0 & 0 & 0 & 0 \\
\hline $\mathrm{X} 25$ & 0 & 0 & 0 & 0 & 0 & 0 & 0 & 0 & 0 & 0 & 0 & 0 & 0 & 0 & 0 & 0 & 0 & 0 & 0 & 0 & 0 & 0 & 0 & 0 \\
\hline X26 & 0 & 0 & 0 & 0 & 0 & 0 & 0 & 0 & 0 & 0 & 0 & 0 & 0 & 0 & 0 & 0 & 0 & 0 & 0 & 0 & 0 & 0 & 0 & 0 \\
\hline $\mathrm{X} 27$ & 3 & 3 & 3 & 3 & 3 & 3 & 3 & 3 & 3 & 3 & 3 & 3 & 3 & 3 & 4 & 3 & 3 & 3 & 3 & 4 & 3 & 3 & 4 & 4 \\
\hline $\mathrm{X} 28$ & 0 & 0 & 0 & 0 & 0 & 0 & 0 & 0 & 0 & 0 & 0 & 0 & 0 & 0 & 0 & 0 & 0 & 0 & 0 & 0 & 0 & 0 & 0 & 0 \\
\hline X29 & 0 & 0 & 0 & 0 & 0 & 0 & 0 & 0 & 0 & 0 & 0 & 0 & 0 & 0 & 0 & 0 & 0 & 0 & 0 & 0 & 0 & 0 & 0 & 0 \\
\hline X30 & 5 & 5 & 5 & 5 & 5 & 5 & 5 & 6 & 5 & 5 & 5 & 5 & 5 & 5 & 5 & 5 & 5 & 5 & 5 & 5 & 5 & 5 & 5 & 5 \\
\hline X31 & 16 & 16 & 16 & 16 & 16 & 16 & 16 & 16 & 16 & 16 & 16 & 16 & 16 & 16 & 16 & 16 & 16 & 16 & 16 & 16 & 17 & 16 & 16 & 16 \\
\hline X32 & 0 & 0 & 0 & 0 & 0 & 0 & 0 & 0 & 0 & 0 & 0 & 0 & 0 & 0 & 0 & 0 & 0 & 0 & 0 & 0 & 0 & 0 & 0 & 0 \\
\hline X33 & 1 & 1 & 1 & 1 & 1 & 1 & 1 & 1 & 1 & 1 & 1 & 1 & 1 & 1 & 1 & 1 & 1 & 1 & 1 & 1 & 1 & 1 & 1 & 1 \\
\hline X34 & 1 & 1 & 1 & 1 & 1 & 1 & 1 & 1 & 1 & 1 & 1 & 1 & 1 & 1 & 1 & 1 & 1 & 1 & 1 & 1 & 1 & 1 & 1 & 1 \\
\hline X35 & 1 & 1 & 1 & 1 & 1 & 1 & 1 & 1 & 1 & 1 & 1 & 1 & 1 & 1 & 1 & 1 & 1 & 1 & 1 & 1 & 1 & 1 & 1 & 1 \\
\hline X36 & 1 & 1 & 1 & 1 & 1 & 1 & 1 & 1 & 1 & 1 & 1 & 1 & 1 & 1 & 1 & 1 & 1 & 1 & 1 & 1 & 1 & 1 & 1 & 1 \\
\hline
\end{tabular}


Wang Y, Shi Q, You Z, Hu Q. Integration Methodology of Spare Parts Supply Network Optimization and Decision-making

Table 7 - Evaluation metrics of decision-making units

\begin{tabular}{|c|c|c|c|c|c|c|c|c|c|c|c|}
\hline & \multicolumn{2}{|c|}{ Input metrics } & \multicolumn{9}{|c|}{ Output metrics } \\
\hline & 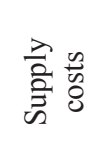 & 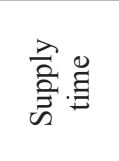 & 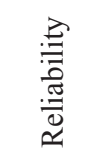 & $\begin{array}{l}\mathscr{n} \\
\stackrel{\mathscr{E}}{\Xi} \\
\stackrel{\Xi}{\Xi}\end{array}$ & 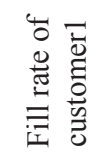 & 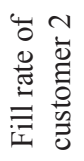 & 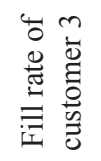 & 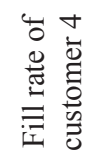 & 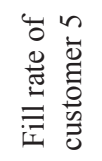 & 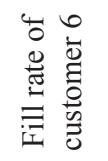 & 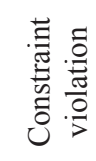 \\
\hline$\overline{\mathrm{DMU}_{1}}$ & 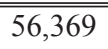 & 3,746 & 0.1054 & 0.0192 & $\overline{c 1}$ & $\overline{c 1}$ & 1.0556 & $\bar{~} 1$ & $\bar{~} 1$ & $\bar{~} 1$ & 0.0033 \\
\hline $\mathrm{DMU}_{2}$ & 57,484 & 3,822 & 0.1070 & 0.0192 & 1 & 1 & 1.0556 & 1 & 1 & 1.0667 & 0.0033 \\
\hline $\mathrm{DMU}_{3}$ & 57,076 & $3,937.5$ & 0.1139 & 0.0192 & 1 & 1 & 1 & 1 & 1 & 1 & 0.0033 \\
\hline $\mathrm{DMU}_{4}$ & 57,336 & $3,972.5$ & 0.1168 & 0.0192 & 1 & 1 & 1 & 1 & 1 & 1 & 0.0033 \\
\hline $\mathrm{DMU}_{5}$ & 57,456 & $3,964.5$ & 0.1164 & 0.0192 & 1 & 1 & 1 & 1 & 1 & 1 & 0.0033 \\
\hline $\mathrm{DMU}_{6}$ & 58,149 & 4,016 & 0.1210 & 0.0192 & 1 & 1 & 1.0556 & 1 & 1 & 1 & 0.0033 \\
\hline $\mathrm{DMU}_{7}$ & 58,101 & $4,097.5$ & 0.1210 & 0.0192 & 1 & 1 & 1 & 1 & 1 & 1 & 0.0033 \\
\hline $\mathrm{DMU}_{8}$ & 59,405 & $3,937.5$ & 0.1149 & 0.0192 & 1 & 1 & 1.1667 & 1.2000 & 1 & 1 & 0.0033 \\
\hline $\mathrm{DMU}_{9}$ & 57,741 & $3,997.5$ & 0.1195 & 0.0192 & 1 & 1 & 1 & 1 & 1 & 1 & 0.0033 \\
\hline $\mathrm{DMU}_{10}$ & 58,909 & 3,987 & 0.1212 & 0.0192 & 1 & 1 & 1.0556 & 1 & 1 & 1.0667 & 0.0033 \\
\hline $\mathrm{DMU}_{11}$ & 56,471 & $3,875.5$ & 0.1063 & 0.0192 & 1 & 1 & 1 & 1 & 1 & 1 & 0.0033 \\
\hline $\mathrm{DMU}_{12}$ & 58,270 & 3,870 & 0.1101 & 0.0192 & 1 & 1 & 1.1667 & 1 & 1 & 1 & 0.0033 \\
\hline $\mathrm{DMU}_{13}$ & 56,846 & $3,903.5$ & 0.1135 & 0.0192 & 1 & 1 & 1 & 1 & 1 & 1 & 0.0033 \\
\hline $\mathrm{DMU}_{14}$ & 57,549 & 3,947 & 0.1157 & 0.0192 & 1 & 1 & 1.0556 & 1 & 1 & 1 & 0.0033 \\
\hline $\mathrm{DMU}_{15}$ & 58,204 & 3,943 & 0.1148 & 0.0192 & 1.0833 & 1 & 1.0556 & 1 & 1 & 1 & 0.0033 \\
\hline $\mathrm{DMU}_{16}$ & 57,411 & $3,974.5$ & 0.1190 & 0.0192 & 1 & 1 & 1 & 1 & 1 & 1 & 0.0033 \\
\hline $\mathrm{DMU}_{17}$ & 57,261 & $3,920.5$ & 0.1139 & 0.0192 & 1 & 1 & 1 & 1 & 1 & 1 & 0.0033 \\
\hline $\mathrm{DMU}_{18}$ & 58,404 & 4,048 & 0.1220 & 0.0192 & 1 & 1 & 1.0556 & 1 & 1 & 1 & 0.0033 \\
\hline $\mathrm{DMU}_{19}$ & 58,171 & $4,083.5$ & 0.1227 & 0.0192 & 1 & 1 & 1 & 1 & 1 & 1 & 0.0033 \\
\hline $\mathrm{DMU}_{20}$ & 58,791 & $4,068.5$ & 0.1230 & 0.0192 & 1.0833 & 1 & 1 & 1 & 1 & 1 & 0.0033 \\
\hline $\mathrm{DMU}_{21}$ & 56,838 & $3,897.5$ & 0.1075 & 0.0192 & 1 & 1 & 1 & 1 & 1.0625 & 1 & 0.0033 \\
\hline $\mathrm{DMU}_{22}$ & 58,507 & $3,907.5$ & 0.1136 & 0.0192 & 1 & 1 & 1.1111 & 1 & 1 & 1.0667 & 0.0033 \\
\hline $\mathrm{DMU}_{23}$ & 57,559 & 3,886 & 0.1096 & 0.0192 & 1.0833 & 1 & 1.0556 & 1 & 1 & 1 & 0.0033 \\
\hline $\mathrm{DMU}_{24}$ & 56,416 & $3,819.5$ & 0.1058 & 0.0192 & 1.0833 & 1 & 1 & 1 & 1 & 1 & 0.0033 \\
\hline
\end{tabular}

Data Envelopment Analysis (DEA)

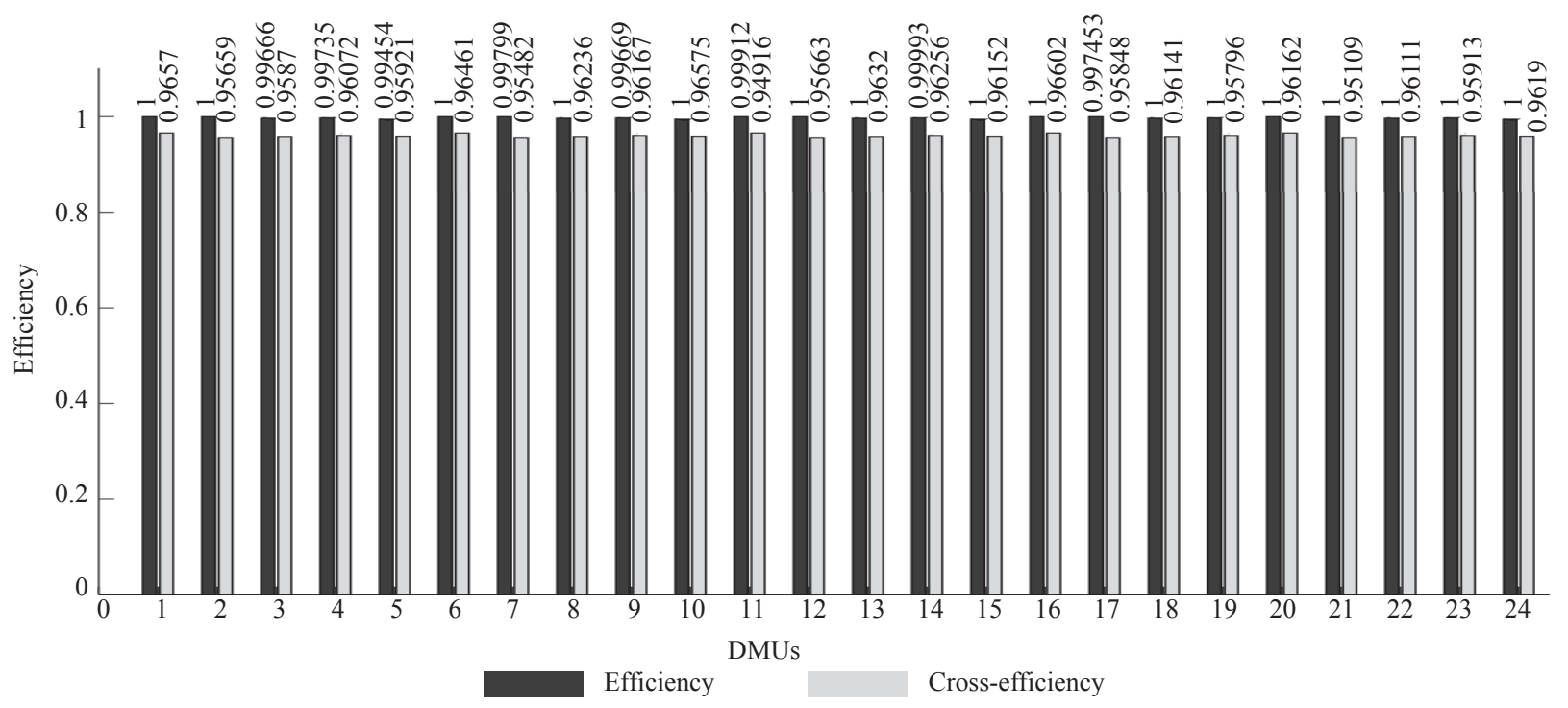

Figure 1-Self-efficiency and cross-efficiency of each decision-making unit 
16 DMUs whose self-evaluation efficiency is equal to 1 , that is, these 16 DMUs are efficient DMUs, and they cannot be sorted just based on the self-evaluation efficiency. This disadvantage can be overcome by our method. As can be seen from Figure 1, all DMUs can be sorted based on their cross-evaluation efficiency, and the optimal supply scheme can be selected. The optimal supply scheme in this case is $D M U_{16}$, and its cross-evaluation efficiency is 0.96602 .

\section{CONCLUSION}

This paper solves the problem of spare parts supply network optimization and evaluation, and a multi-objective optimization model considering time, risk and cost is developed. To solve the model, the differential evolution strategy is introduced into the MOEA/D algorithm, and the non-dominated solutions of the model are obtained by using the proposed multi-objective evolution algorithm. In order to further make a decision on the optimal solutions, a series of quantitative metrics is selected to evaluate these supply schemes comprehensively from the aspects of reliability, timeliness, and economy. The improved cross-efficiency DEA model is used to overcome the defects of traditional CCR model that the efficient DMUs cannot be sorted and the weights are not unique. All DMUs are sorted based on their cross-efficiency, and the optimal scheme is selected.

The main contributions of this paper are as follows. Firstly, a framework for formulating, solving and evaluating the spare parts supply problem in wartime is provided. Secondly, the Pareto solutions obtained by multi-objective optimization are further evaluated and sorted by the DEA model. Thirdly, the efficient DMUs are sorted by cross efficiency which cannot be done in traditional DEA model. Finally, the unique optimal weight combination can be obtained by using secondary goals strategy. The model and algorithm of this paper provide a framework for formulating the spare parts supply and the solving method to obtain the optimal supply scheme.

王亚东, 陆军工程大学, 装备指挥与管理系。河北 省石家庄市新华区和平西路97号。邮编: 050003. 邮 箱: xwzj0003@gmail.com

石全, 陆军工程大学, 装备指挥与管理系。河北省 石家庄市新华区和平西路97号。邮编：050003. 邮 箱: airesearch01@gmail.com

尤志锋, 陆军工程大学, 装备指挥与管理系。河北
省石家庄市新华区和平西路97号。邮编：050003. 邮 箱: junshiyc@163.com

胡起伟, 陆军工程大学, 装备指挥与管理系。河北 省石家庄市新华区和平西路97号。邮编：050003. 邮

箱: wana96100@gmail.com

\section{备件供应网络优化决策方法研究}

\section{摘要}

为了对备件供应网络进行优化, 本文首先以最短 时间、最低风险和最少成本为目标建立了多目标优 化模型。其次, 采用差分进化策略下基于分解的多 目标优化算法求解模型。最后, 再利用改进数据包 络分析法对非支配解集进行评估。通过对比自评效 率和互评效率找出有效方案、无效方案以及最优方 案。

\section{关键词}

备件供应; 多目标优化; 数据包络分析; 交叉效率

\section{REFERENCES}

[1] $\mathrm{Hu}$ Q, Boylan JE, Chen H, et al. OR in spare parts management: A review. European Journal of Operational Research. 2018;266(2): 395-414.

[2] Wei G, Yang Y. Dispatching model of continuous consumption resources in wartime under insufficient supply. Systems Engineering and Electronics. 2012;34(1): 102106.

[3] Liu X, Zhu Y-G, Wang W-P. Optimizing wartime multiphase spares support. Systems Engineering and Electronics. 2006;44(8): 238-241.

[4] Zhang S, Guo J, Zhong F, et al. Multi-objective Material Provision Mission Planning under Battlefield Fuzzy Environment. Mathematics in Practice and Theory. 2015;45(13): 90-95.

[5] Qin J, Ye Y, Shen C, et al. Optimization method for emergency resource layout for transportation network considering service reliability. Journal of Railway Science and Engineering. 2018;15(2): 506-514.

[6] Fazli Khalaf M, Khalilpourazari S, Mohammadi M. Mixed robust possibilistic flexible chance constraint optimization model for emergency blood supply chain network design. Annals of Operations Research. 2019;283: 1079-1109. Available from: doi:10.1007/s10479-0172729-3

[7] Zhang J, Liu H, Yu G, et al. A three-stage and multi-objective stochastic programming model to improve the sustainable rescue ability by considering secondary disasters in emergency logistics. Computers \& Industrial Engineering. 2019;135: 1145-1154. Available from: doi:10.1016/j.cie.2019.02.003

[8] Mohammadi R, Ghomi SMTF, Jolai F. Prepositioning emergency earthquake response supplies: A new multi-objective particle swarm optimization algorithm. Applied Mathematical Modelling. 2016;40(9-10): 51835199.

[9] Su Z, Zhang G, Liu Y, et al. Multiple emergency resource allocation for concurrent incidents in natural disasters. 
International Journal of Disaster Risk Reduction. 2016;17: 199-212.

[10] Mardle S, Miettinen KM. Nonlinear Multiobjective Optimization. Journal of the Operational Research Society. 2000;51(2): 246

[11] Zhang Q, Li H. MOEA/D: A Multiobjective Evolutionary Algorithm Based on Decomposition. IEEE Transactions on Evolutionary Computation. 2008;11(6): 712-731.

[12] Messac A, Ismail-Yahaya A, Mattson CA. The normalized normal constraint method for generating the Pareto frontier. Structural and Multidisciplinary Optimization. 2003;25(2): 86-98.

[13] Zhang L, Bi X, Wang Y. The $\varepsilon$ Constrained Multi-objective Decomposition Optimization Algorithm Based on Re-matching Strategy. Acta Electronica Sinica. 2018;423(05): 11-19.

[14] Panda A, Pani S. A Symbiotic Organisms Search algorithm with adaptive penalty function to solve multi-objective constrained optimization problems. Applied Soft Computing. 2016;46: 344-360.

[15] Coello CAC. Constraint-Handling Techniques used with
Evolutionary Algorithms. Conference Companion on Genetic \& Evolutionary Computation Conference: Late Breaking Papers, ACM, Philadelphia; 2012. p. $2445-$ 2466.

[16] Khezrimotlagh D, Zhu J, Cook WD, et al. Data Envelopment Analysis and Big Data. European Journal of Operational Research. 2019;274: 1047-1054. Available from: doi:10.1016/j.ejor.2018.10.044

[17] Chen J. Research on the improvement of the Model and Evaluation method of Super-efficient data Envelopment Analysis. Zhejiang University, China; 2011.

[18] Doyle J, Green R. Efficiency and Cross-efficiency in DEA: Derivations, Meanings and Uses. Journal of the Operational Research Society. 1994;45(5): 567-578.

[19] Liang L, Wu J, Cook WD, et al. Alternative secondary goals in DEA cross-efficiency evaluation. International Journal of Production Economics. 2008;113(2): 10251030.

[20] Wang YM, Chin KS. Some alternative models for DEA cross-efficiency evaluation. International Journal of Production Economics. 2010;128(1): 332-338. 